\title{
Consumo de noticias en línea por los estudiantes universitarios de Quito
}

\section{Digital news consumption by the university students of Quito}

DOI: https://doi.org/10.29166/tyc.v1i19.2076

\section{Julio Mauricio Carrión Campoverde}

Estudiante de la Facultad de Comunicación Social de la Universidad Central del Ecuador. Entre sus líneas de investigación están los análisis de recepción de mensajes con acento en los medios digitales. Así también desarrolla investigaciones sobre narrativas mediáticas.

Correo: juliomcc24@gmail.com

\section{Resumen}

El contexto informativo mundial ha cambiado vertiginosamente por el uso de internet y sus diferentes plataformas y redes sociales. Actualmente tenemos acceso a información en vivo y en distintos formatos. Las noticias ya no son transmitidas solo por la radio, la televisión o la prensa escrita, sino también por internet. En este artículo se analiza el consumo de noticias en línea por parte de los estudiantes universitarios de Quito: para qué y qué tipo de noticias. También se analiza el contexto del alfabetismo mediático en el que están inmersos los estudiantes y de dónde provienen estos: ciencias sociales o ciencias naturales.

Palabras clave: estudiantes, noticias, alfabetismo mediático, internet, consumo

\section{Abstract}

The global information context has changed dramatically due to the use of the internet and its different platforms and social networks. We currently have access to live information and in different formats. The news is no longer only transmitted by radio, television or the written press, but also through the Internet. This article analyzes the consumption of digital news by university students in Quito: for what and what kind of news. The context of media literacy in which students are immersed and where they come from: Social Sciences or Natural Sciences.

Keywords: students, news, media literacy, internet, consumption. 


\section{Introducción}

En el siglo XXI gran parte de la información ha pasado de un modelo analógico a uno digital. Con el surgimiento de internet y las redes sociales, la información que se difunde en los medios de comunicación ha tenido muchos cambios. Para entender este entramado digital se debe conocer cómo y de dónde surge la información; cómo ha sido creada; cómo acceder e interactuar con ella. El término que engloba lo antes mencionado es la "alfabetización mediática", y se lo puede entender, según Rivera-Rogel et al. (2019) como:

\begin{abstract}
una expresión que abarca una amplia gama de capacidades técnicas, cognitivas y sociales necesarias para que un ciudadano tenga una postura crítica ante los medios de comunicación. Sin embargo, el concepto de alfabetización mediática no es estático, y es que evoluciona constantemente, es dinámico como la sociedad. Razón por la cual, el conocimiento en torno a los medios digitales y los medios convencionales debe ser amplio $(2019,14)$.
\end{abstract}

Lo anterior nos pone en contacto con la situación actual de la información que circula en las redes sociales y la web en general. Las redes sociales se han convertido en una de las principales fuentes de información. Según el estudio Reuters Digital News Report (2014), más del 60\% de los menores de 35 años emplea como segunda fuente de información Facebook, Twitter, Linkedin (que están solo por detrás de la televisión), etc. Mientras que los más jóvenes, de entre 18 y 24 años, utilizan las redes sociales como su fuente principal de información.

Esto nos hace recordar una reflexión de Raymond Williams (1974) quien hace más de cuatro décadas ya planteaba que: "Cuando una tecnología alcanza su pleno desarrollo, puede considerársela como una propiedad humana general, una extensión de la capacidad humana general" (165). Y es que, con el avance tecnológico, las noticias digitales están al alcance de cualquier persona que logre ingresar en internet.

De modo similar, Jean Marabini (1974) planteaba: "El medio de pensar modifica el pensamiento. Cuando este medio es la escritura, el pensamiento toma una determinada forma, y toma otra forma cuando la escritura no existe" (68). Tanto la escritura, los videos o cualquier otro formato en el que se encuentre la información, incidirá directamente en el pensamiento de quien consume la información. "El pensamiento ha forjado el instrumento, pero este instrumento a su vez modela el pensamiento" (68).

\section{Información en medios no convencionales}

Es importante reconocer que la revolución de las tecnologías de la información, debido a su capacidad de penetración en todos los ámbitos de la actividad humana, representan un punto de entrada para analizar la complejidad de la nueva economía, la sociedad y la cultura en formación. Cuando determinados sucesos impactan en la vida de las personas, estas se pronuncian en las redes sociales y expresan su aprobación, desacuerdo o cualquier otra sensación al respecto. En la mayoría de los casos, la inmediatez juega un papel predominante. Esto genera una interrogante que ya fue planteada por Raymond Williams en el contexto de los avances tecnológicos de su época: 
Como descripciones de cualquier estado o tendencia social observable, en el período en el que los medios electrónicos han sido dominantes, estas descripciones son tan disparatadas que plantean una nueva interrogante, el hecho físico de la transmisión instantánea, como posibilidad técnica, se ha elevado, sin ningún análisis crítico, al nivel del hecho social, sin hacer tampoco ninguna pausa para señalar que casi toda esta transmisión está inmediatamente seleccionada y controlada por autoridades sociales existentes. $(1974,163)$

En este sentido, Manuel Castells (1997), en un contexto más contemporáneo nos dice: "La aparición de un nuevo sistema de comunicación electrónico, caracterizado por su alcance global, su capacidad de integración de todos los medios de comunicación y su interactividad potencial, está cambiando nuestra cultura, y lo hará para siempre" (399). La integración de la que habla este autor significa que los medios tradicionales y los medios digitales se unen y esa unión puede variar mucho los usos que de ellos hacen las audiencias.

\section{El panorama en el Ecuador}

Si aplicamos estas ideas al contexto ecuatoriano, vemos que este país no está fuera del contexto mundial de la sociedad en red. No obstante, presenta algunas dificultades respecto, principalmente, la educación y la alfabetización mediática, como lo señalan Rivera-Rogel, et al:

Una revisión de los resultados de varios estudios sobre el estado actual de la educación en alfabetización mediática en Ecuador señala que se tiene que dar una mayor importancia al componente pedagógico que al tecnológico, ya que se han demostrado falencias y vacíos tanto en los profesores como en los estudiantes en todos los niveles a pesar de contar con acceso a la tecnología. $(2019,18)$
Esto significa que la información que circula en internet carece de una recepción con valor pedagógico. Es decir, los estudiantes universitarios son parte del fenómeno de analfabetismo mediático. Ya lo advirtió en su tiempo el propio Willams:

Al mismo tiempo, estamos en una situación muy conflictiva y confusa respecto de las instituciones y los procesos sociales de todas las comunicaciones. Todavía no han terminado las largas luchas y discusiones sobre las instituciones y el control de la difusión extendida de sonidos e imágenes, es decir, el conflicto -que para dos generaciones estuvo muy claro- entre instituciones "públicas” y “comerciales". (1974, 173)

Por esta razón el consumo de noticias digitales es una arista de la comunicación, que debe ser analizado en los diferentes niveles educativos. Y cómo no analizarla desde el consumo de quienes se están formando para ser profesionales, ya que ellos deberían tener el conocimiento necesario acerca de la información digital, el uso y sus respectivas aplicaciones. Más que todo, tener una noción clara del entorno comunicacional donde se desarrollan las noticias que se consumen por medio de internet y dispositivos electrónicos.

En este artículo exploratorio me he trazado como objetivo principal analizar el consumo de noticias digitales por los estudiantes universitarios de Quito. Para ello, examino las noticias en redes sociales y sitios web; identifico el tipo de noticias más consumido; y procuro determinar la frecuencia con que los estudiantes acceden a estas. He delimitado el estudio a los estudiantes de tercer nivel o también llamado pregrado.

Partiendo de las corrientes de investigación vigentes en recepción de medios, he optado por las relacionadas con 
los efectos de los medios. Las investigaciones procedentes de esta corriente han partido, por lo general, de la pregunta: ¿Qué hacen los medios con la audiencia?

Guillermo Orozco (2000) nos dice que los efectos de los medios se enmarcan en distintas temporalidades y crean cierto tipo de conducta que puede observarse y hasta medirse (54-55) El tipo de estudio o el alcance es descriptivo, ya que se refiere al valor del dato en sí mismo. El enfoque es mixto, puesto que ha sido fundamentado por medio del análisis estadístico (cuantitativo), resultado de la recolección de datos, con el análisis de textos y otros documentos (cualitativo) que fueron la base para poder orientar la investigación. Escogí la encuesta como técnica de recolección de datos.

\section{Consumo de noticias en línea}

En el Ecuador todavía no se consolida una cultura digital y mediática. En ese aspecto, los estudiantes universitarios, aunque en su mayoría son nativos digitales, no forman parte de un índice considerable de alfabetismo mediático. Entonces surgen preguntas como: ¿Existe o no, un alto consumo de noticias en medios no-convencionales? Quienes acceden a la información digital ¿poseen el conocimiento y las técnicas necesarias para la obtención de información?, entre otras.

Fueron diez las preguntas de la encuesta para este análisis. Preguntas abiertas (para permitir una diversidad de criterios) y preguntas cerradas (para la recolección de datos). El universo de estudiantes fue de 94.819 que corresponde a las seis universidades de Quito analizadas. La muestra calculada fue de 662 estudiantes. Los resultados tienen un margen de error calculado en un $5 \%$.

Segmentamos las carreras en dos grupos: Ciencias Sociales y Ciencias $\mathrm{Na}-$ turales, de la siguiente manera:

\begin{tabular}{|l|l|}
\hline \multicolumn{1}{|c|}{ Universidades públicas } & \multicolumn{1}{c|}{ Universidades privadas } \\
\hline Carreras que provienen de Ciencias Sociales & Carreras que provienen de Ciencias Sociales \\
\hline Carreras que provienen de Ciencias Naturales & Carreras que provienen de Ciencias Naturales \\
\hline
\end{tabular}

La recolección de los datos e información se llevó a cabo entre abril y julio de 2019 en las siguientes universidades:

\begin{tabular}{|l|l|}
\hline \multicolumn{1}{|c|}{ Públicas } & \multicolumn{1}{c|}{ Privadas } \\
\hline Escuela Politécnica Nacional (EPN) & Universidad Internacional del Ecuador (UIDE) \\
\hline Universidad Central del Ecuador (UCE) & Universidad de las Américas (UDLA) \\
\hline & Universidad Tecnológica Equinoccial (UTE) \\
\hline & Universidad San Francisco de Quito (USFO) \\
\hline
\end{tabular}




\section{Resultados}

La mayoría de los estudiantes de universidades, tanto públicas como privadas, son consumidores de noticias de medios digitales, redes sociales, sitios web y otros espacios. Más de la mitad consume estas noticias seis o más veces por semana. Esto indica que consumen una o más noticias de estos medios por día.

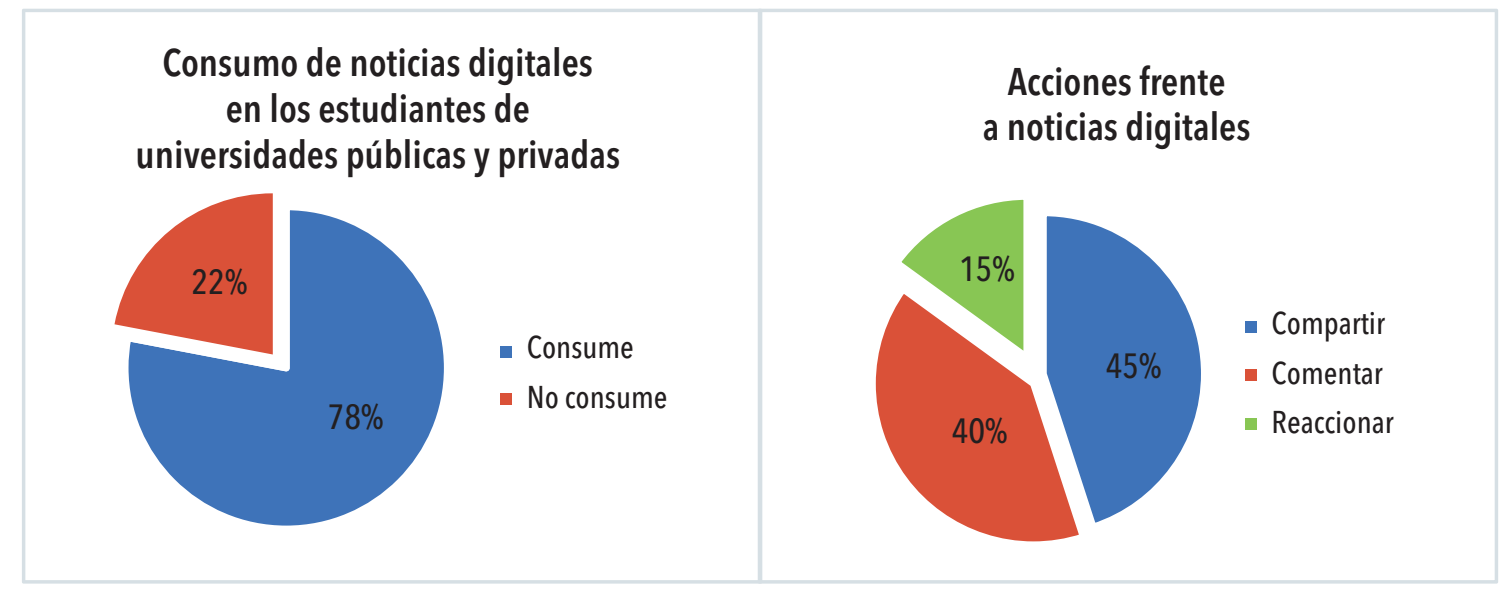

Estos primeros resultados fueron bastante importantes ya que muestran que gran parte de los estudiantes consumen por lo menos una noticia en línea al día. Como nos dice John B. Thompson (1998): "En un proceso de apropiación, con frecuencia los mensajes se transforman, ya que los individuos los adaptan a contextos prácticos de la vida cotidiana" (230).

Los estudiantes de las facultades de ciencias sociales, mayoritariamente, comparten y comentan las noticias en línea que son de su interés directo. Los estudiantes de las facultades de ciencias naturales, mayoritariamente, solo reaccionan a estas noticias, es decir, otorgan un "me gusta" u otra opción que se encuentra en la plataforma informativa; en menor grado reaccionan y comparten la información leída.

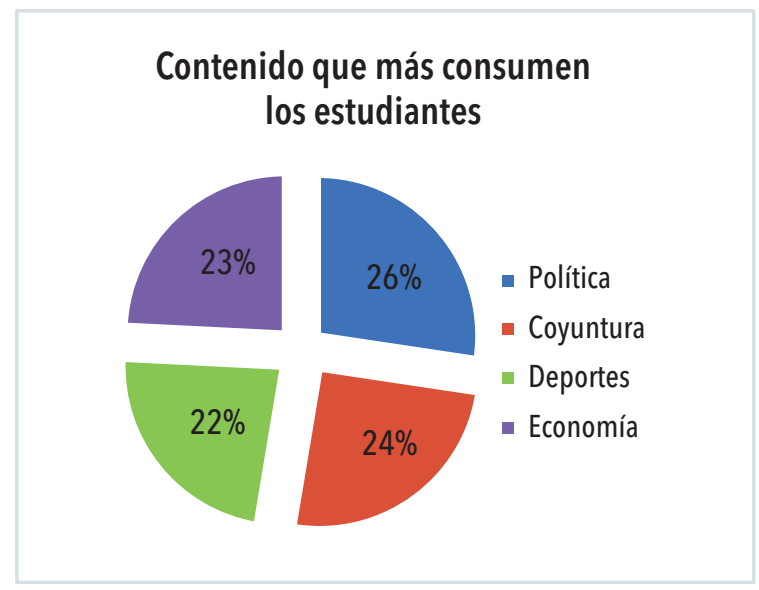


Los estudiantes de las facultades de ciencias sociales consumen más noticias de política y coyuntura. Mientras que los estudiantes de ciencias naturales consumen noticias relacionadas con deportes y economía. En cuanto al contenido de las noticias, se tiene en cuenta que los sistemas de comunicación están conectados e interrelacionados. Como podemos darnos cuenta: política, economía, coyuntura, deportes, etc. De esta manera, se configuran las programaciones o las secciones de las noticias. Y cualquiera de ellas puede captar rápidamente la atención de los consumidores.

\section{Conclusiones}

En un contexto donde los índices de alfabetismo mediático son bajos, vemos que el consumo de noticias digitales es alto. Cuando este tipo de consumo se desarrolla en un entorno de alfabetismo mediático bajo, la información recibida no puede ser entendida con su valor real y contextual; recibir información sin suficiente conocimiento del medio en que se produce ayuda a que la percepción de la realidad sea bifurcada o distorsionada.

También se puede entender el consumo por el tipo de noticias: deportes, política, economía, coyuntura, puesto que las preferencias de unas y otras dependen del tipo de carrera a la que pertenecen los estudiantes. Este dato es importante como base para pensar en procesos de alfabetización mediática principalmente en ámbitos digitales.

\section{BibLiOgRAFía}

Castells, M. (1997). La era de la información: economía, sociedad y cultura. Volumen I. la sociedad red. Madrid: Alianza Editorial, S.A.

Marabini, J. (1974). Marcuse \& Mcluhan y la nueva revolución mundial. Valencia: Editorial con solapas.

Orozco, G. (2000). La investigación en comunicación desde la Perspectiva Cualitativa. Guadalajara: Instituto Mexicano para el Desarrollo Comunitario, A.C.

Rivera-Rogel D., Mier C., Rodríguez-Hidalgo C., Andrade L., Iriarte M., Marín-Gutiérrez I., ... Freire, R. (2019). "Libro Blanco. Competencias mediáticas en Ecuador". Pearson, 8-82. Recuperado de: http://www.redalfamed.org/libros

Thompson, J. (1998). Los media y la modernidad Una teoría de los medios de comunicación. Barcelona: Editorial Paidós. Williams, R. (1974). Televisión Tecnología y forma cultural. Barcelona: Paidós. 